\title{
Research on Suspension System Based on Genetic Algorithm and Neural Network Control
}

\author{
Chuan-Yin Tang and Li-Xin Guo*
}

School of Mechanical Engineering and Automation, Northeastern University, Shenyang 110004, China

\begin{abstract}
In this paper, a five degree of freedom half body vehicle suspension system is developed and the road roughness intensity is modeled as a filtered white noise stochastic process. Genetic algorithm and neural network control are used to control the suspension system. The desired objective is proposed as the minimization of a multi-objective function formed by the combination of not only sprung mass acceleration, pitching acceleration, suspension travel and dynamic load, but also the passenger acceleration. With the aid of software Matlab/Simulink, the simulation model is achieved. Simulation results demonstrate that the proposed active suspension system proves to be effective in the ride comfort and drive stability enhancement of the suspension system. A mechanical dynamic model of the five degree of freedom half body of vehicle suspension system is also simulated and analyzed by using software Adams.
\end{abstract}

\section{INTRODUCTION}

Suspension is the term given to the system of springs, shock absorbers and linkages that connects a vehicle to its wheels. Suspension systems can not only contribute to the car's handling and braking for good active safety and driving pleasure, but also keep vehicle occupants comfortable and reasonably well isolated from road noise, bumps, and vibrations. The suspension also protects the vehicle itself and any cargo or luggage from damage and wear. The ride quality of a vehicle is significantly influenced by its suspension system, the road surface roughness, and the speed of vehicle. A vehicle designer can do little to improve road surface roughness, so designing a good suspension system with good vibration performance under different road conditions become $\mathrm{s}$ a prevailing philosophy in the automobile industry. Passive suspension systems use conventional dampers to absorb vibration energy, the dampers and stiffness coefficients are constant. The active suspension system use extra power to provide a response-dependent damper, which is capable of producing an improved ride comfort. Over the years, both passive and active suspension systems have been proposed to optimize a vehicle's ride quality. O. GD used genetic algorithm to obtain the optimal set and suspension design (O. GD. IJIE 2007) [1], Sun L, Cai XM, Yang J. got the minimum dynamic pavement load through the genetic algorithm (Sun L, Cai XM, Yang J. JSV 2007) [2]. A simplified algorithm for the evaluation of a small car suspension model can be found in the papers of T.G. Chondros (T.G. Chondros, S. Michalitsis, S. Panteliou and A.D. Dimarogonas 1994) [3] and (T.G. Chondros, P.A. Belokas, K. Vamvakeros and A.D. Dimarogonas 1997) [4], Furthermore, a more detailed model for heavy vehicles suspension systems are given in the paper (Chondros T. G.,

*Address correspondence to this author at the School of Mechanical Engineering and Automation, Northeastern University, Shenyang 110004, China; E-mail: 1xguo@mail.neu.edu.cn
Michalos G, Michaelides P, Fainekos E 2007) [5]. The stateof-the-art review on neural networks in automotive applications can be found in the papers (J.T. Papadimitropoulos, T.G. Chondros, S.D. Panteliou, B. Carlsson, S. Kalogirou and A.D. Dimarogonas 1999) [6] and (S. Kalogirou, T.G. Chondros, A.D. Dimarogonas 2000) [7].

A variety of research projects and publications deal with different types of active suspension systems have been discussed (Yeh, E.C. and Tsao, Y.J. 1994) [8]. Different vehicle dynamic models have been adopted according to different study purposes during research. A two degree-of freedom quarter body of vehicle suspension system model had been widely applied in vehicle suspension control research, it can indicate the vehicle body vertical movement, but not include the pitching movement of the vehicle body. Although a seven degree-of -freedom whole-body of vehicle suspension system model can describe not only the vertical movement of the four wheels and the body center of gravity, but also the pitching and lateral movement, the model is too complicated to be widely applied. 'In our research, a fivedegree-of -freedom half body of vehicle suspension system model is established, which can describe both the vertical movement and the pitching movement of the body, what's more, it can demonstrate the effect of the passenger, which makes it to be a relatively ideal model for suspension dynamic description.

From the flow chart before using ADAMS, we can see that the mechanical engineer and the control engineer use different software, build repeated model for one concept design, moreover, different design validation and tests are made. Once there is something wrong, no matter what kind of fault appears, both the mechanical system and the control system will have to be designed again. Fig. (1) shows the flow chart before using ADAMS, and Fig. (2) shows the flow chart after using ADAMS.

From Fig. (2), the flow chart after using ADAMS, we can see that the mechanical engineer and the control engineer share the same virtual model, thus the mechanical design can 


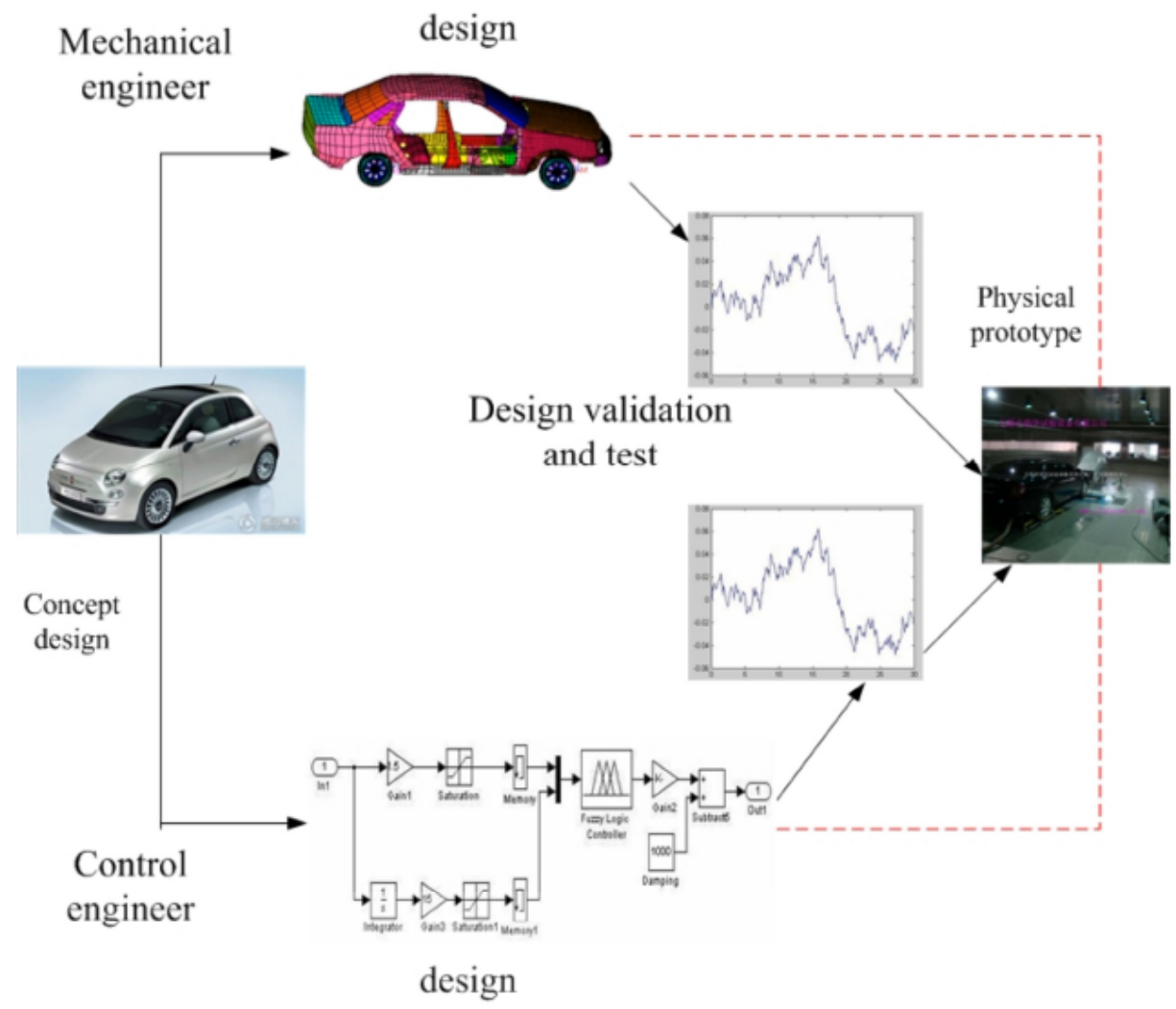

Fig. (1). The flow chart before using ADAMS.

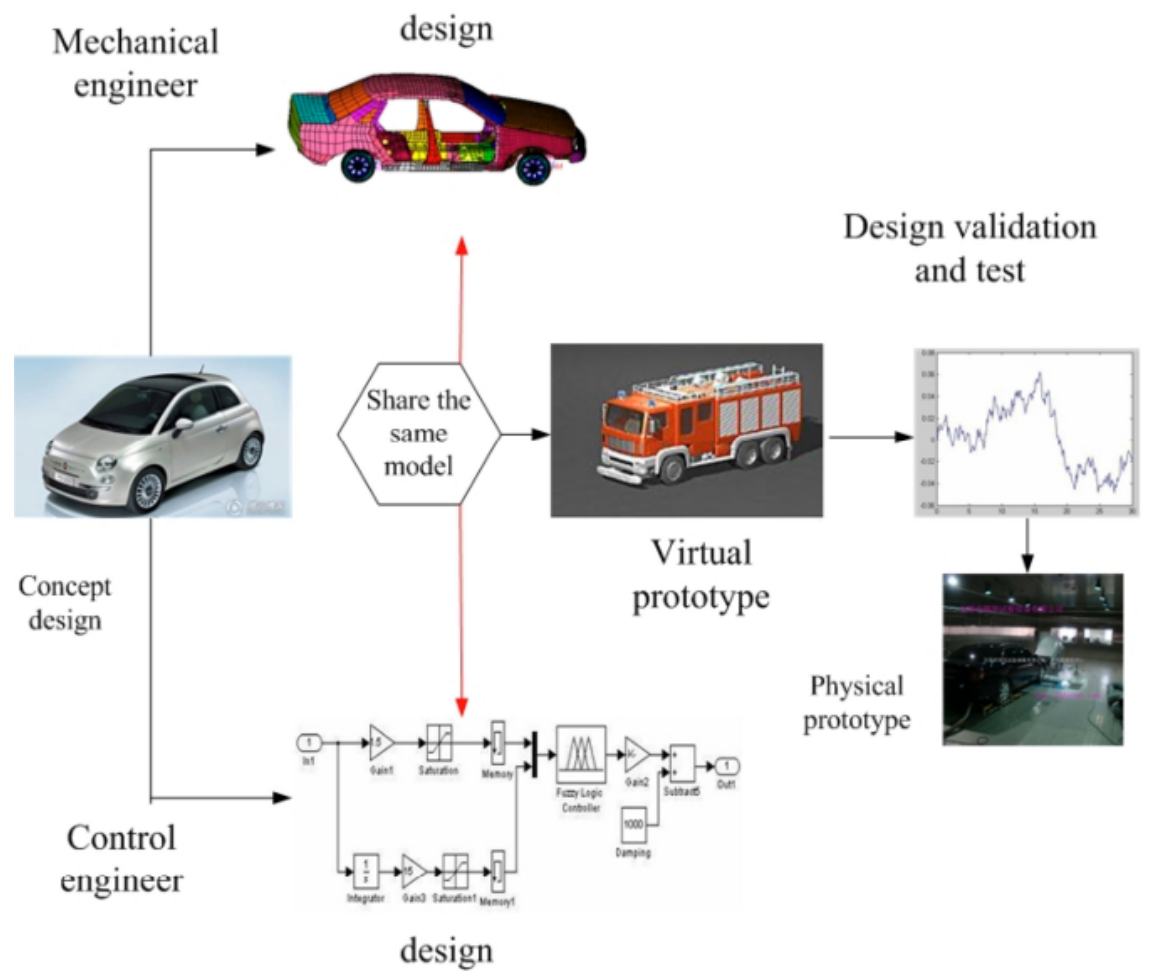

Fig. (2). The flow chart after using ADAMS.

correspond with the control design. Furthermore, more complex model, such as the nonlinear model can be obtained, and design time is decreased and the design reliability is improved.
The paper proposes an active suspension system for vehicles, using the genetic and neural network algorithm to control the system, which integrates the merits of two algorithms. A mechanical dynamic model of the five degrees 


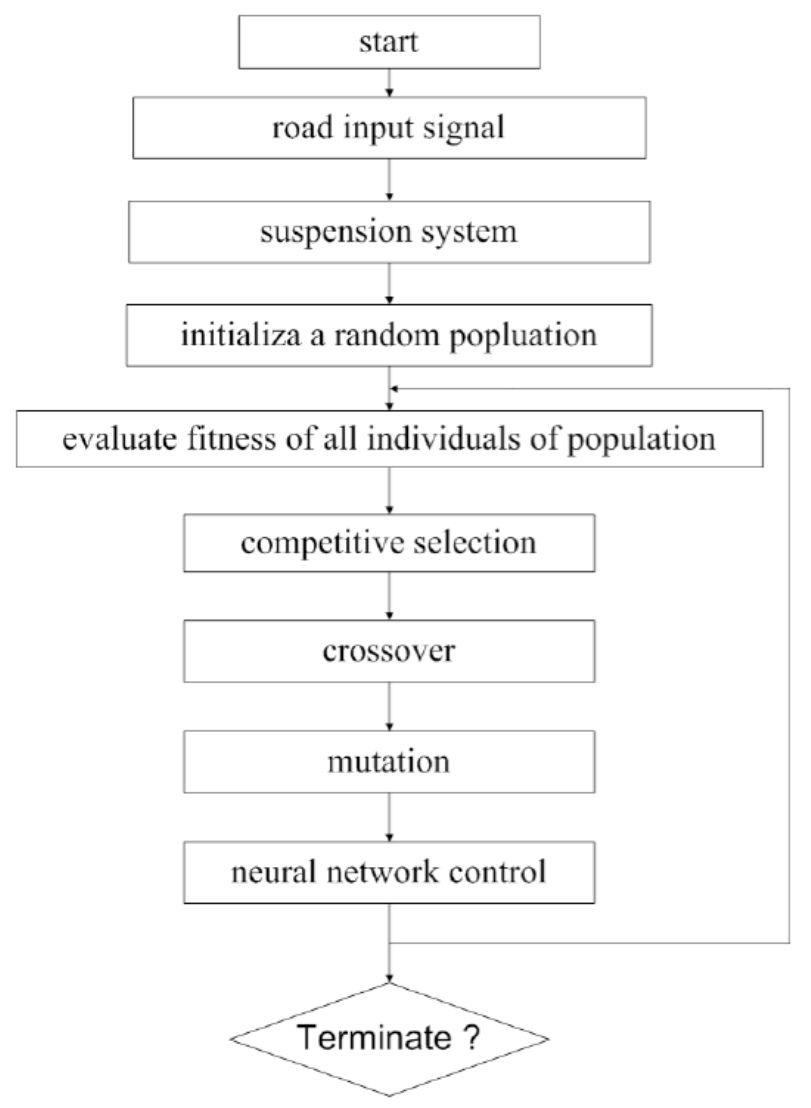

Fig. (3). Model of five degrees of freedom of suspension system.

of freedom half body of vehicle suspension system is also simulated and analyzed by using software Adams. Computer simulations demonstrate the effectiveness of the proposed system.

\section{VEHICLE MODEL}

A schematic diagram of active suspension control system is shown in Fig. (3). The half-body suspension system is represented as a five degrees of freedom system.

The assumptions during the process of modeling are considered as following: (1) the irregular road excitation of the left tire and right tire is same, the vehicle is symmetrical to the longitudinal line, thus the roll and yaw movement is omitted; (2) the vehicle body, including the engine part is considered as a rigid body, which means the effect of engine is neglected. The vehicle consists of a single sprung mass connected to two unsprung masses and the passenger mass; (3) the axle and the tires connected are regarded as the unsprung mass, the contact manner of the center tire line and the road is point to point method; (4) the tires are modeled as simple linear springs without damping. For simplicity, all pitch angles are assumed to be small (Yu. ZS. 2002) [9].

The essence of the control of the semi-active suspension is the regulation of the adjustable shock absorber, thus the nonlinearity of the adjustable shock absorber is the main characteristics of nonlinear suspension model. For simplicity, tires are still assumed as the linear elements. The shock absorber indicate strong nonlinearity during certain region. The shock absorber is partitioned as the fundamental dam- ping and the controller damping, and the controller damping can be separated as the control force, thus only the fundamental damping of the adjustable shock absorber is considered during modeling. The adjustable throttle orifice hydraulic shock absorber can obtain the regulation of the damping through the control of angles of the stepping motor.

According to the different peculiarity of extend and compress stroke, the relationship of damping force and the velocity of the shock absorber is considered as followings (Zhou LK. 2005) [10]:

$F=C V$

$$
\begin{aligned}
& \text { If } V<0 \text { then } C=1034 \mathrm{Ns} / \mathrm{m} ; \\
& \text { If } V<0 \text { then } C=2502 \mathrm{Ns} / \mathrm{m}
\end{aligned}
$$

Where $F$ is the damping force, $V$ is the velocity of the shock absorber, $C$ is the fundamental damping.

The relationship between the is adopted, which is expressed as following:

$$
\begin{aligned}
& \theta=1000 \times\left(-0.5012 c^{4}+2.9153 c^{3}\right. \\
& \left.+-6.2572 c^{2}+5.8246 c-1.9370\right)
\end{aligned}
$$

Where $\theta$ is the angle of the stepping motor; $c$ is the average damping of adjustable shock absorber. With the aid of matlab file $M$, the nonlinear differential equation can be obtained by programming.

After applying a force- balance analysis to the model in Fig. (1) the dynamics equation is governed by, 


$$
\begin{aligned}
& m_{s} \ddot{Z}_{1}+f_{k s}+f_{c s}=0 \\
& m \ddot{Z}_{2}+f_{k f}+f_{k r}+f_{c f}+f_{c r}-f_{k s}-f_{c s}=0 \\
& \ddot{\theta}+b\left(f_{k r}+f_{c r}\right)+e\left(f_{k s}+f_{c s}\right)-a\left(f_{k f}+f_{c f}\right)=0 \\
& m_{f} \ddot{Z}_{4}+f_{k t f}-f_{k f}-f_{c f}=0 \\
& m_{r} \ddot{Z}_{6}+f_{k t r}-f_{k r}-f_{c r}=0
\end{aligned}
$$

The system states are expressed as follows:

$f_{k s}=K_{s}\left[Z_{1}-Z_{3}-(a-e)\left(Z_{5}-Z_{3}\right) / L\right] ; f_{c s}=C_{s}\left[Z_{1}-Z_{3}-(a-e)\left(Z_{5}-\dot{Z}_{3}\right) / L\right]$, are the seat spring force and seat damping force, respectively; $f_{k f}=K_{f}\left(Z_{3}-Z_{4}\right)$ and $f_{k r}=K_{r}\left(Z_{5}-Z_{6}\right)$ are the front suspension spring force and rear suspension spring force, , respectively; $f_{c f}=C_{f}\left(\dot{Z}_{3}-Z_{4}\right)$ and $f_{c r}=C_{r}\left(\dot{Z}_{5}-Z_{6}\right)$ are the front suspension damping force and rear suspension damping force, respectively; where the coefficients $C_{f}$ and $C_{r}$ come from Equation (1). $f_{k f f}=K_{t f}\left(Z_{4}-Z_{01}\right)$ and $f_{k t r}=K_{t r}\left(Z_{6}-Z_{02}\right)$ are front tire spring and force rear tire spring force.

This results in the system state equations below:

$X=\left[\begin{array}{llllllllllllll}X_{1} & X_{2} & X_{3} & X_{4} & X_{5} & X_{6} & X_{7} & X_{8} & X_{9} & X_{10} & X_{11} & X_{12} & X_{13} & X_{14}\end{array}\right]^{T}$ $=\left[\begin{array}{llllllllllllll}Z_{1} & Z_{2} & Z_{3} & Z_{4} & Z_{5} & Z_{6} & Z_{1} & Z_{2} & Z_{3} & Z_{4} & Z_{5} & Z_{6} & Z_{01} & Z_{02}\end{array}\right]^{T}$ The state

space equations in matrix are given by $X(t)=A X(t)+B W(t)$, with the disturbance input defined as $W=\left[\begin{array}{ll}w_{1} & w_{2}\end{array}\right]^{T}$.

\section{GENETIC ALGORITHM AND NEURAL NETWORK CONTROL}

Genetic algorithm is a stochastic global search method which is based on the metaphors of natural biological evolution, according to Darwin (1809-1882) evolution theory. Genetic algorithm has abilities that differ substantially from more traditional search and optimization methods. Neural network provides a fast method for autonomously learning to produce a set of output states, given a set of input states. The emergence of neural networks as effective learning systems for a wide variety of applications has resulted in the use of these networks as learning models for dynamical systems (Wang YJ 2007) [11]. One of the important advantages of using neural networks for control applications is that the dynamics of the controlled system need not be completely known as a prior condition for controller design. This is a very desirable feature in the design of the controller, because of the nonlinearities arising from rigid-body coupling. The ability of networks and adaptation and their highly parallel nature of computation make approach suitable for real time and simulations applications.

The combination of neural network and genetic algorithm is one methods of the scientific optimization arithmetic. The proportion of the index, the spring mass and the suspension stiffness have important influence on the stability of the system.

There are three characteristics commonly used to access the performance of vehicle suspension system. (1) ride comfort, which improves as the magnitude of the seat acceleration is reduced; (2) system stability, which is acceptable for restricted or low tire road contact forces and is quantified by tire deflection; (3) the suspension travel, which must be restricted.

To consider the ride comfort and drive stability synthetically, the spring mass acceleration, tire dynamic load and suspension deflection are selected as the significant indexes for the evaluation of active suspension control effect, and the weighted objective function is generally defined by the following equation:

$J=\rho_{1} z_{2}^{2}+\rho_{2} \ddot{\theta}^{2}+\rho_{3} \ddot{z}_{1}^{2}+\rho_{4} \frac{y_{f}^{2}+y_{r}^{2}}{2}+\rho_{5} \frac{\left(z_{1 f}-z_{0 f}\right)^{2}+\left(z_{1 r}-z_{0 r}\right)^{2}}{2}$

And $y_{f}=z_{3}-a \theta-z_{4} \quad y_{r}=z_{2}+b q-z_{6} ; z_{1}$ is the passenger displacement; $z_{2}$ is the vehicle body vertically displacement $\theta$ is the pitching angle.

The fitness function $f$ is given by $f=\frac{1}{J}$.

Ride quality as the suspension system design criterion mainly stems from taking a human ride comfort perspective. P. E. Uys investigates the spring and damper settings that will ensure optimal ride comfort of an off-road vehicle on different road profiles and at different speeds (P. E. Uys. JF. 2007) [12].

On the other hand, from a cost-effectiveness of vehicle infrastructure system perspective, another performance measure is also of significant importance, that is, the dynamic tire load applied on the road. Thus, the objective function includes not only the sprung mass acceleration, the sprung pitching acceleration, but also the suspension deflection and the dynamic tire load. And $\rho_{1}, \rho_{2}, \rho_{3}, \rho_{4}, \rho_{5}$ are the weighted coefficients of the sprung mass acceleration the sprung pitching acceleration the passenger acceleration the suspension deflection and the dynamic tire load, respectively.

The general steps of genetic algorithm and neural network are shown by a chart in Fig. (4).

To take advantage of genetic algorithms as well as neural network, we implement the combination of genetic algorithm and neural network in this paper to solve the vehicle suspension problem. 


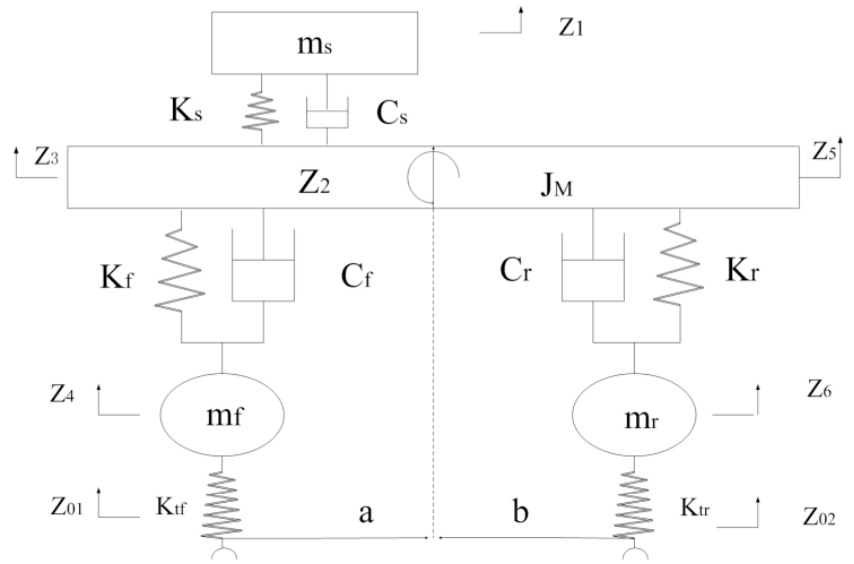

Fig. (4). Schematic diagram of the system.

\section{Crossover}

This is the exchange of chromosomes characteristics among randomly selected pairs from the parent root. The crossover rate has proper value, the excessive large value will damage the excellent mode, and the excessive small value will decrease the velocity of new chromosome. In the present work, 0.5 is the considered probability rate of the crossover.

\section{Mutation}

This operator executes by switching zero with one, at a binary bit. Mutation is randomly applied with low probability, typically in the range of $0.01-0.1$. Here, a value of 0.01 is the considered for mutation probability.

The NN of this active control system has two hidden layers, the input, hidden and output neurons are 1, 10, 3 and 1 , respectively. The advanced back propagation is adopted and we added momentum in the back propagation to prevent the network from getting stuck in a shallow local minimum point. An adaptive learning rate was applied to decrease the training by keeping the learning reasonably high while insuring stable learning. We pick random values as initial weights and biases.

(1) The input of NN is the time response of the acceleration of sprung mass, the objective output is the optimized suspension control force. The transfer function is nonlinear function.

$$
y=\frac{2}{1+e^{-x}}-1 .
$$

(2) The objective function $E_{p}$ is determined as:

$$
E_{p}(t)=\frac{1}{2} \sum_{k}\left[d_{k p}-y_{k p}(t)\right]^{2}
$$

Where $y_{k p}(t)$ is the network output after $t$ times weighting factors adjusting, with the $p$ th sample applied to the network. And $k$ is the $k$ th neuron of the output layer.

The mathematical expression of back propagation wit momentum can be written as: $w_{i j}(t+1)=w_{i j}(t)-\eta(t) \sum_{p} \frac{\partial E_{p}(t)}{\partial w_{i j}(t)}+\alpha \Delta w_{i j}(t)$

To get variable $\eta$ from function,

$F d=\left\{\begin{array}{l}\min f(w(t+1)-f(w(t))) \\ \text { s.t. } \eta \geq 0\end{array}\right.$

Where $\delta_{m_{1} p}$ is sensitivity degree value of the $m_{1}$ th neuron's state $x_{m_{1} p}$ with $E_{p} \quad m_{1}$ is the $m_{1}$ th neuron of next layer of neuron $i ; \eta$ is the learning coefficients and $\alpha$ is the coefficient of momentum.

\section{SIMULATION RESULTS}

To verify the validity of the method, the paper includes a great deal of calculating process based on the simulation software "Matlab/Simulink". The performance of the active control scheme is illustrated through a series of simulations.

Denoting the irregular road excitation as band limited white noise, which is determined by different road surface condition and velocity, the equations (ISO 2631-1:1997 (E)) [13] of font and rear road are expressed as following:

$$
\begin{aligned}
& z_{01}(t)=-2 \pi f_{0} z_{01}(t)+2 \pi \sqrt{G_{q} V_{0}} \omega_{1}(t) ; \\
& z_{02}(t)=-2 \pi f_{0} z_{02}(t)+2 \pi \sqrt{G_{q} V_{0}} \omega_{2}(t)
\end{aligned}
$$

Where $f_{0}$ is the lowest frequency irregular road coefficients $G_{q}\left(n_{0}\right)=256 \times 10^{-6} \mathrm{~m}^{2} / \mathrm{m}^{-1}$ and velocity is $20 \mathrm{~m} / \mathrm{s}$.

The NN controller with optimal acceleration parameters computed by GA-based optimization is designed as follows: The NN uniformed the input data and objective matrix, and revert the output result to the actual range. If the fitting tolerance of testing samples are within the desired, the NN perform normally, and save the weighting factors, otherwise, print" the network is over-fitting and can not work properly". In the NN simulations system, a momentum value of 0.9 , error ratio value of 1.04 , and an adaptive learning rate value of 0.01 with an increase multiplier of 1.05 and a decrease multiplier of 0.6 were applied to speed up the training time. The initial population size is 45 ; the end number is 100 ; set the probability of crossover to be 0.5 , and the mutation probability to be 0.01 .

Fig. (5) indicates the controlled system and the passive system sprung mass vertical acceleration response. For compare, they are shown in one figure. The dash line represents the system before control, and the solid line indicates the system after control. Fig. (6) shows the controlled pitching angular acceleration response and the passive system pitching angular acceleration response. And Fig. (7) shows the controlled acceleration response and the passive system acceleration response of passenger. Then Fig. (8) demonstrates the front suspension travel response. Figs. (9 and 10) presents the dynamic front and rear tire load response, respectively. From these figures, we can see that the vertical 
control of the sprung mass and passenger accele-ration is decreased by the controlled systems, which indi-cates that the GA\&NN control system is effective in impro-ving the system ride comfort. The response of suspension travels and the dynamic tire deflections emphasizes the fact that the controlled system can improve the system stability.

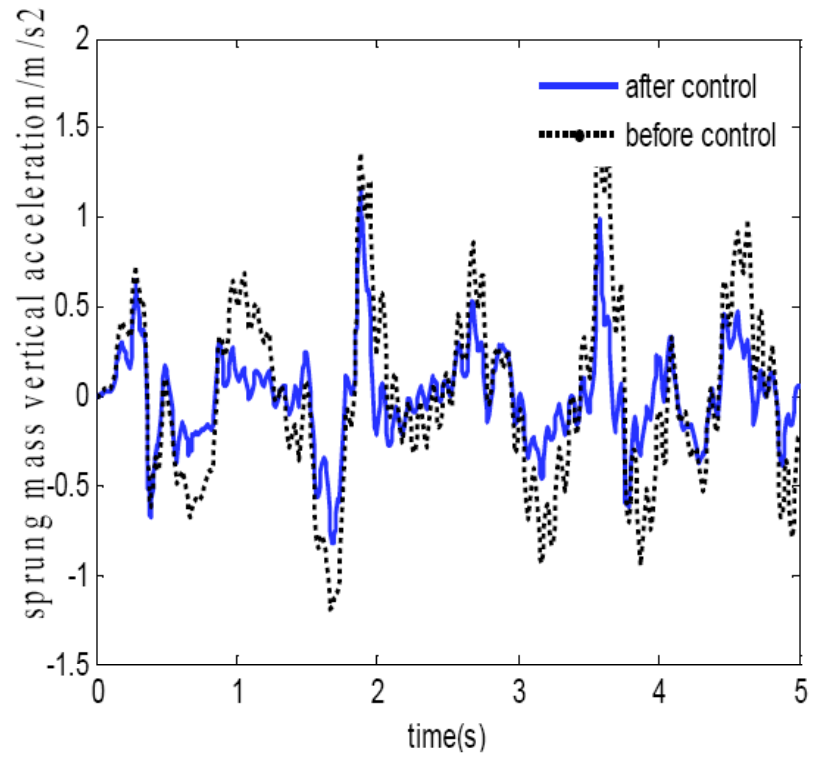

Fig. (5). Sprung mass vertical acceleration response.

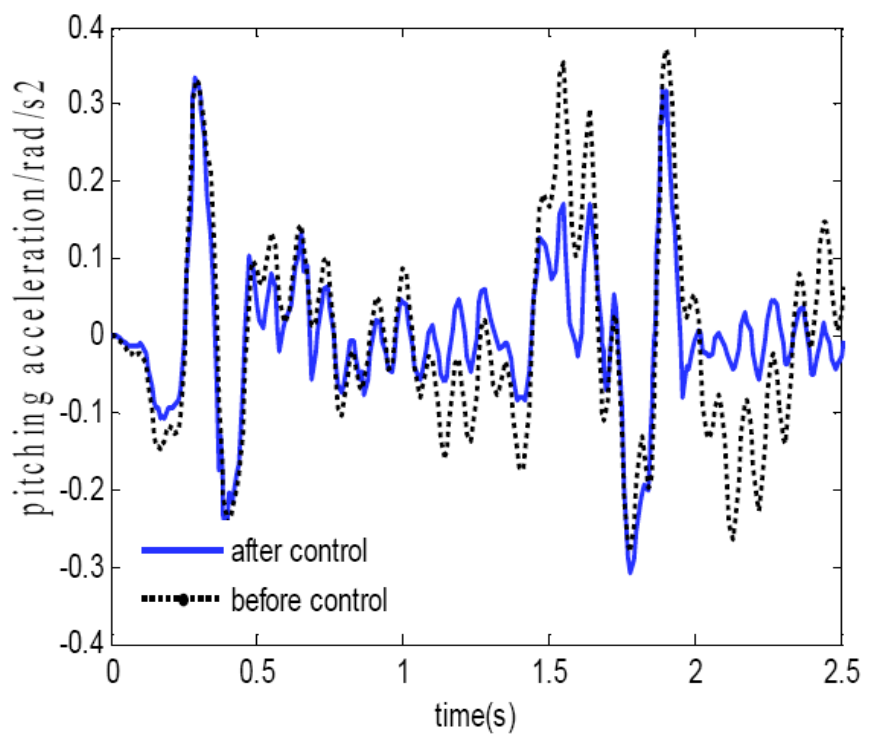

Fig. (6). Pitching angular acceleration response.

Table 1 includes the performance analysis of the system. The body acceleration and pitching angular acceleration is greatly decreased, and the passenger acceleration is reduced dramatically, which indicates that the genetic algorithm and neural network controller is effective in improving the system riding comfortability. The tire dynamic load is reduced, which indicates that the system stability is meliorated.

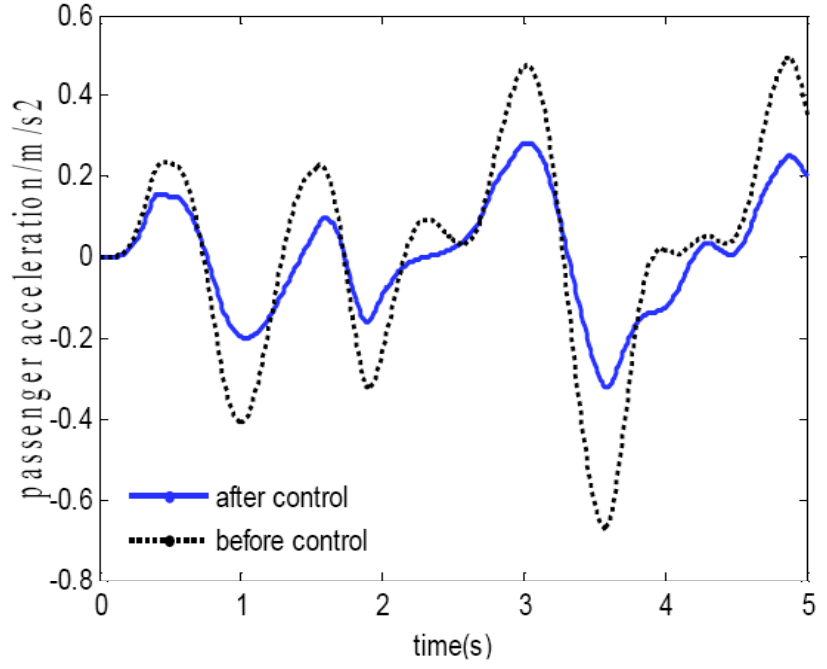

Fig. (7). Passenger vertical acceleration response.

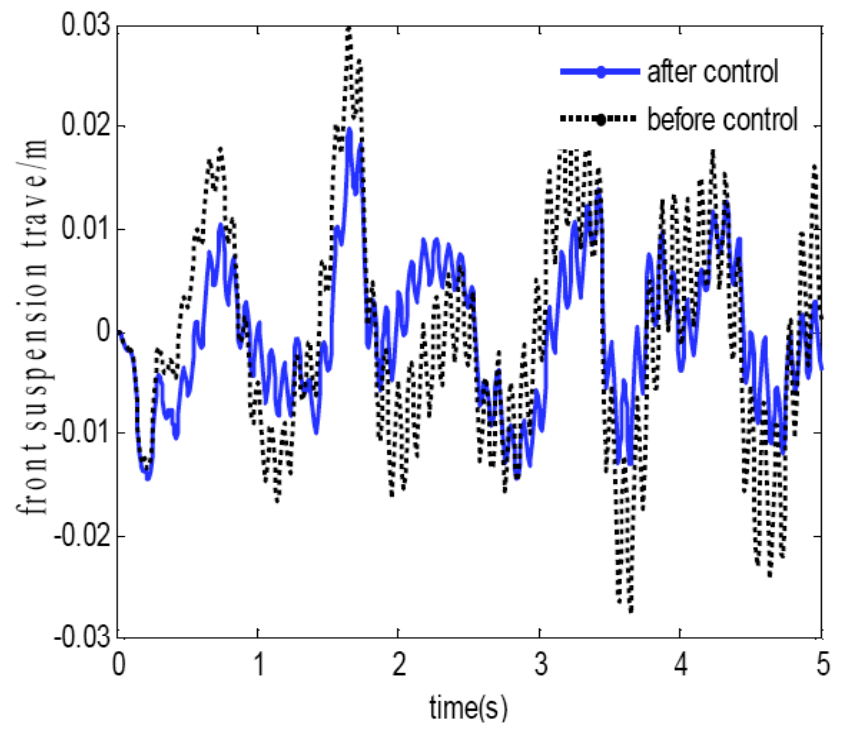

Fig. (8). Front suspension travel response.

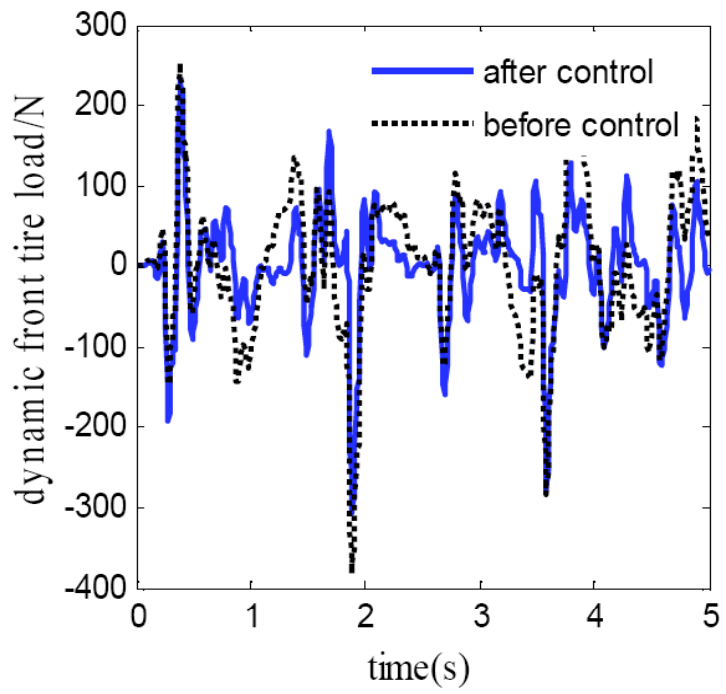

Fig. (9). Dynamic front tire load response. 


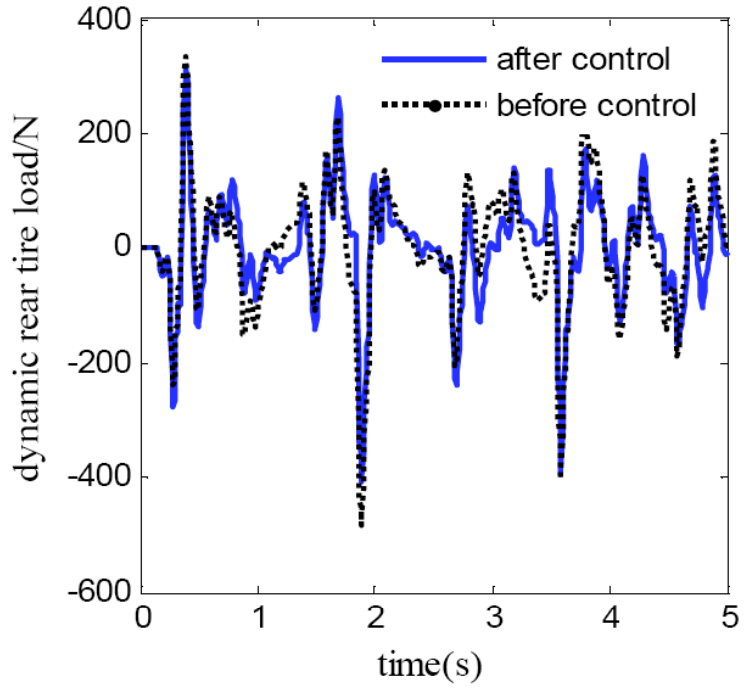

Fig. (10). Dynamic rear tire load response.

Table 1. Performance Analysis

\begin{tabular}{|c|c|c|}
\hline & $\begin{array}{l}\text { Body Acceleration } \\
(\mathrm{m} / \mathrm{s} 2)\end{array}$ & $\begin{array}{l}\text { Pitching Angular } \\
\text { Acceleration (rad/s2) }\end{array}$ \\
\hline Before control & 0.4620 & 0.1745 \\
\hline After control & 0.2524 & 0.1226 \\
\hline \multirow[t]{2}{*}{$\begin{array}{c}\text { Performance } \\
\text { melioration }\end{array}$} & $45.4 \%$ & $29.7 \%$ \\
\hline & $\begin{array}{c}\text { Passenger } \\
\text { Acceleration }(\mathrm{m} / \mathrm{s} 2)\end{array}$ & $\begin{array}{l}\text { Front suspension travel } \\
\qquad(\mathrm{m})\end{array}$ \\
\hline Before control & 0.2109 & 0.0089 \\
\hline After control & 0.1150 & 0.0058 \\
\hline $\begin{array}{l}\text { Performance } \\
\text { melioration }\end{array}$ & $45.5 \%$ & $34.8 \%$ \\
\hline Before control & $\begin{array}{c}\text { Front tire dynamic } \\
\text { load }(\mathrm{N})\end{array}$ & $\begin{array}{l}\text { Rear tire dynamic load } \\
\text { (N) }\end{array}$ \\
\hline After control & 82.8 & 102.5 \\
\hline $\begin{array}{l}\text { Performance } \\
\text { melioration }\end{array}$ & 61.4 & 89.9 \\
\hline Before control & $25.8 \%$ & $12.3 \%$ \\
\hline
\end{tabular}

\section{ASSOCIATED SIMULATION}

First, using the software ADAMS, the mechanical model of five DOF suspension system is established (Chen Y 2007) [14], as shown in Fig. (11). The ADAMS model is imported into the Matlab/Simulink model, to accomplish the associated simulation with Matlab/Simulink (Chen LP 2007) [15]. Figs. (12 and 13) indicate the vertical acceleration and pitching angular acceleration response of the sprung mass of the constituted mechanical model. The solid line is the curve of matlab simulation, the dash line is the curve of combination of matlab and Adams. From the results, we can see that although the variation trend of the vertical response and the pitching acceleration response of the established mathematical model and the mechanical are in consistence, there is difference between the solid line and the dash line. The method of modeling of matlab and Adams differs from each other. Through matlab/simulink we constitute the suspension model; for Adams, the virtual mechanical model is constituted by plentiful accessory storeroom of Adams, such as the vehicle body, the wheel and the spring part, then we have to inflict the restriction between the components, the restriction between the components constitutes the difference between the matlab response and the Adams response.

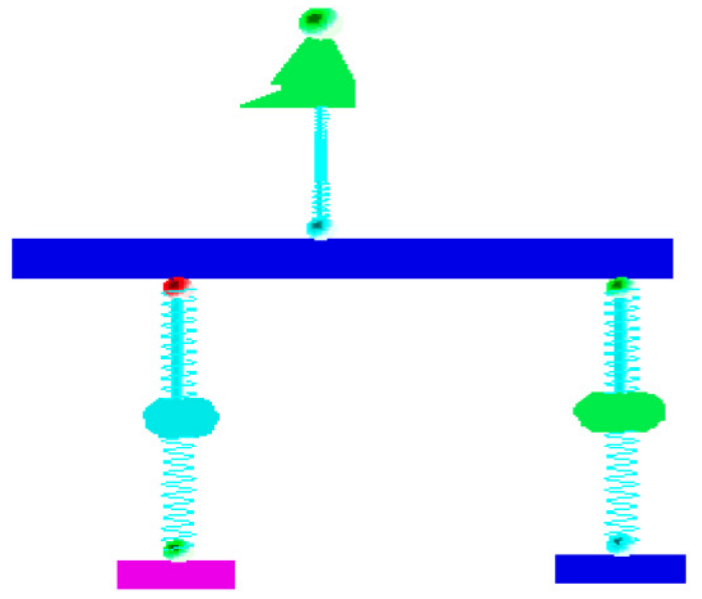

Fig. (11). Mechanical dynamic model.

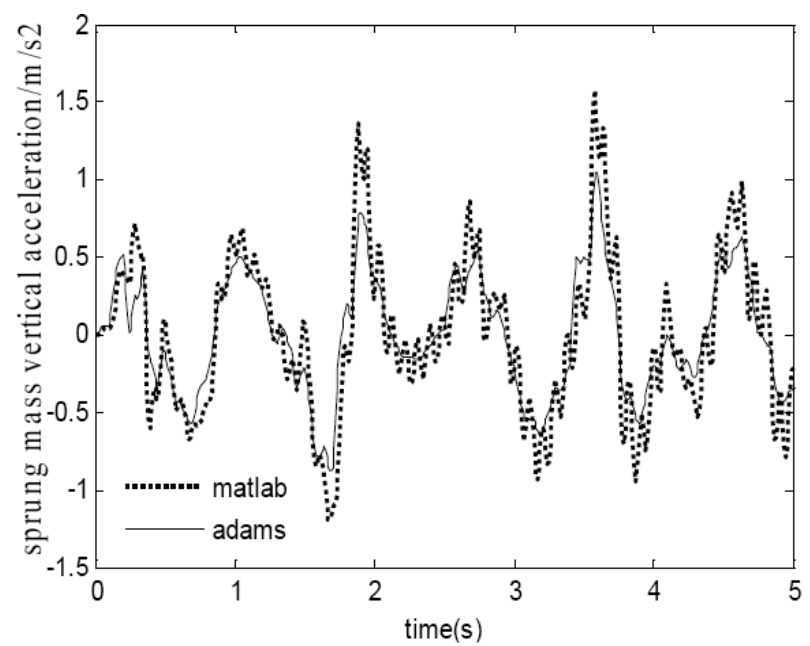

Fig. (12). Sprung mass vertical acceleration response.

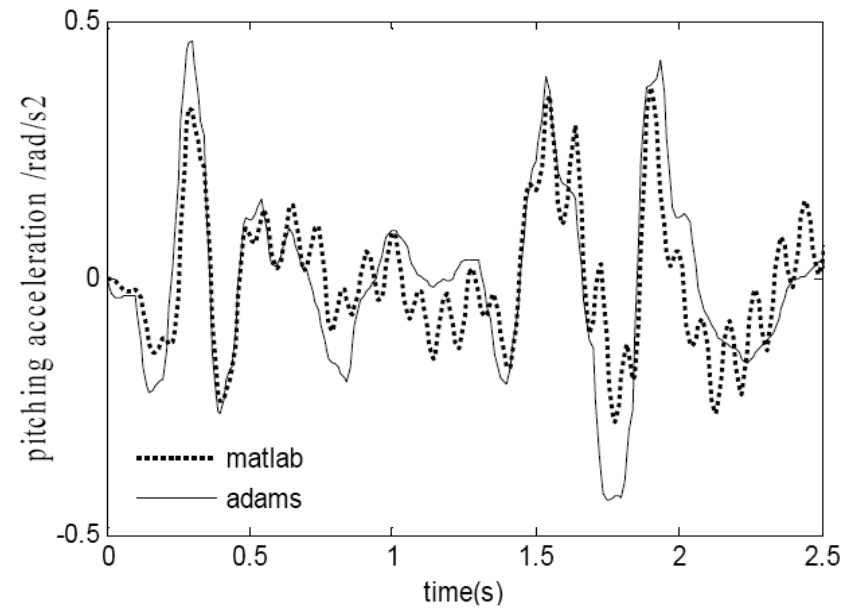

Fig. (13). Pitching angular acceleration response. 


\section{CONCLUSIONS}

In this work, the specified half body vehicle model with passenger involving five degree of freedom is presented to achieve the excellent ride comfort and drive stability of the system. The model is assumed to have five masses attached with linear springs and nonlinear dampers. It is also assumed that the system does not vibrate in lateral direction, only oscillates in vertical and longitudinal directions. Furthermore, the tires are assumed not losing the contact with the road surface. Approaches are presented for suspension design which uses genetic algorithm and neural network control algorithm. It is obvious from the response plots that vehicle body vertical acceleration, passenger response and pitching angular response decreased compared with the passive suspension system, which naturally brings ride comfort. And the suspension travel and dynamic load reduced compared with the passive suspension system, which indicates that the proposed controller proves to be effective in the stability improvement of the suspension system.

\section{ACKNOWLDGEMENTS}

Thanks for the funds supported by National Science Foundation of China (50875041) and Western Communications Construction Project, Research Institute of Highway (2005031822322).

\section{REFERENCES}

[1] O. GD, "Optimal seat and suspension design for a quarter car with driver model using genetic algorithms", International Journal of Industrial Ergonomics, vol. 37, pp. 327-332, 2007.

[2] L. Sun, X. M. Cai, and J. Yang, "Genetic algorithm-based optimum vehicle suspension design using minimum dynamic pavement load as a design criterion", Journal of Sound and Vibration, vol. 301, pp.18-27, 2007.
[3] T. G. Chondros, S. Michalitsis, S. Panteliou, and A. D. Dimarogonas, "Chassis design for a small electric city car", Society of Automotive Engineers Special Publication, vol.1023, pp. 5-12, 1994.

[4] T. G. Chondros, P. A. Belokas, K. Vamvakeros, and A. D. Dimarogonas, "Vehicle dynamics simulation and suspension system design", SAE Steering and Suspensions Technology, vol.1223, pp.169-180, 1997.

[5] T. G. Chondros, G. Michalos, P. Michaelides, and E. Fainekos, "An approximate method for road tankers roll stiffness evaluation", Proceedings of the Institution of Mechanical Engineers, Part D, Journal of Automobile Engineering, vol. 221, pp.1499-1512, 2007.

[6] J. T. Papadimitropoulos, T. G. Chondros, S. D. Panteliou, B. Carlsson, S. Kalogirou, and A. D. Dimarogonas, "Advances in electric vehicle technology", Expert system for energy management of electric cars, SAE Technical Paper Series, SP-1417, 01-1154, 1999.

[7] S. Kalogirou, T. G. Chondros, and A. D. Dimarogonas, "Development of an artificial neural network based fault diagnostic system of an electric car", 01-1154. Reprinted from Design and Technologies for Automotive Safety - Critical Systems 2000 SAE Technical Paper Series SP-1507, 1999.

[8] E. C. Yeh, and Y. J. Tsao, " A fuzzy preview control scheme of active suspension for rough road", International. Journal of Vehicle Design, vol.15, pp.166-180, 1994.

[9] Z. S. Yu, Automobile Theory, Beijing: China Machine Press, 2002, pp. 170-182.

[10] L. K. Zhou, Study on Fuzzy Dynamic System Design and Test of Semi-Active Suspension, Jiangshu: Jiangshu University, 2005.

[11] Y. J. Wang, Analysis of Vehicle Suspension Control Using Neural Networks, Shenyang: Northeastern University, 2007.

[12] P. E. Uys, P. S. Els, and M. Thoresson, "Suspension settings for optimal ride comfort of off-road vehicles travelling on roads with different roughness and speeds", Journal of Terramechanics, vol. 44, pp.163-175, 2007.

[13] Mechanical vibration and shock-Evaluation of human exposure to whole-body vibration-Part 1: General requirements, ISO 2631-1: 1997 (E).

[14] Y. Chen, "Active Suspension System of Automobile Based on Fuzzy Control', Shenyang: Northeastern University, 2007.

[15] L. P. Chen, Mechanical System Dynamic Analysis and ADAMS Application Tutorial, Beijing: Tsinghua University Press, 2005, pp. 80-120.

\section{(C) Tang and Guo; Licensee Bentham Open.}

This is an open access article licensed under the terms of the Creative Commons Attribution Non-Commercial License (http: //creativecommons.org/licenses/by$\mathrm{nc} / 3.0 /$ ), which permits unrestricted, non-commercial use, distribution and reproduction in any medium, provided the work is properly cited. 